\title{
Programas de escrita inventada desenvolvidos com crianças do pré-escolar
}

\author{
Margarida Cid Proença, Andreia da Silva Reis, Margarida Alves Martins \\ Centro de Investigação em Educação (CIE-ISPA), Portugal
}

\begin{abstract}
Resumo
O presente estudo testou a eficácia de dois programas de escrita inventada com crianças do pré-escolar. Partiu-se da hipótese de que ambos seriam eficazes no desenvolvimento da escrita das crianças dos grupos experimentais face ao grupo de controlo. Entre os dois programas a sequência de apresentação das palavras foi variável, mas todas surgiam de materiais usados em jardim-de-infância. Participaram 61 crianças com idades de 5 e 6 anos. Os resultados indicaram diferenças significativas no número global de letras corretamente escritas, na comparação dos dois grupos experimentais com o de controlo, não se tendo encontrado diferenças entre os dois grupos experimentais.

Palavras-Chave: escrita inventada; programas de intervenção; pré-escolar
\end{abstract}

\section{Introdução}

As crianças, antes do ensino formal da leitura e escrita, vão desenvolvendo os primeiros passos para se tornarem leitores-escritores e, nas suas tentativas de descoberta da escrita convencional, vão produzindo as suas escritas.

Alguns autores referem-se a estas escritas como escritas inventadas (Chomsky, 1970; Read, 1971) ou concetualizações infantis sobre a linguagem escrita (Ferreiro \& Teberosky, 1999) para descrever a forma como as crianças, antes do ensino formal, se exprimem na escrita.

Vários estudos experimentais têm utilizado as escritas inventadas das crianças com o intuito de promover o desenvolvimento de competências que facilitam a aprendizagem da linguagem escrita (e.g., Alves Martins, Albuquerque, Salvador \& Silva, 2013; Alves Martins, Salvador \& Albuquerque, 2014; Alves Martins, Salvador, Albuquerque \& Silva, 2014; Alves Martins \& Silva, 2006, 2009; Ouellette \& Sénéchal, 2008; Ouellette, Sénéchal \& Haley, 2013). De facto, os programas de escritas inventadas levam a que as crianças reflitam sobre as produções escritas, sobre a relação entre o oral e o escrito e que vão mobilizando o conhecimento de sons e letras e, assim, possibilitam experiências adequadas de exploração e aprendizagem de competências que facilitam a aquisição da escrita e da leitura (Adams, 1998; Alves Martins \& Silva, 2009; Ouellette \& Sénéchal, 2008; Treiman, 1998).

Nestes estudos são constituídos grupos equivalentes em relação à idade, nível de desenvolvimento cognitivo, consciência fonológica e número de letras conhecidas, dado estas serem variáveis que estão relacionadas com a aprendizagem da leitura e da escrita. Uns grupos são sujeitos a programas de intervenção de escritas inventadas e outros funcionam como grupo de controlo, em que a sua intervenção não tem relação com a linguagem (Alves Martins, Mata \& Silva, 2014).

Os programas de intervenção de escritas inventadas que têm vindo a ser traçados em Portugal seguem determinados pressupostos, sendo que nas sessões se procura criar situações em que se confrontam as crianças com uma escrita alfabética de uma hipotética criança da mesma idade, no sentido de promover e gerar conflito cognitivo e levar à reflexão sobre a escrita. Desenvolvidos dentro da Zona de Desenvolvimento Proximal das crianças, os programas de intervenção promovem a evolução do domínio da escrita (Vygotsky, 1978). Procura-se então que as crianças tenham um papel ativo e participativo no seu processo de aprendizagem e construção do conhecimento acerca da leitura e da escrita, sendo que o objetivo é provocar contradições na informação e, deste modo, gerar dúvidas que levam as crianças a rever as suas conceptualizações sobre a linguagem escrita.

As primeiras investigações, realizadas com crianças portuguesas, começaram por desenvolver este tipo de programas de forma individual, mas recentemente começou-se também a desenvolvê-los em pequenos grupos. Os programas variam entre 5 a 10 sessões, com a duração de 15 a 20 minutos no máximo, que decorrem duas vezes por semana. Nas sessões iniciais começa-se por utilizar palavras facilitadoras, em que o som da primeira sílaba coincide com o nome da letra trabalhada na sessão, no sentido de facilitar a mobilização, por parte das crianças, da letra associada ao som (e.g. para as crianças mobilizarem a letra " $p$ ", pede-se em primeiro lugar para escreverem a palavra "pena", em que a primeira sílaba coincide com o nome dessa letra) (Alves Martins \& Silva, 1999; Mann, 1993). O material linguístico utilizado nas sessões é ainda organizado de modo a que, nas primeiras sessões, sejam apresentadas palavras em que a $1^{\mathrm{a}}$ letra seja sempre a mesma e que, a introdução de várias letras por sessão, seja progressiva (Alves Martins, Mata \& Silva, 2014; Alves Martins \& Silva, 2001).

Os resultados dos diversos estudos experimentais, quer com programas individuais ou em pequeno grupo, têm então demonstrado que as crianças do grupo experimental, nas avaliações do pós-teste, utilizam mais letras convencionais para representar as palavras, independentemente do nível inicial em que se encontravam e, principalmente, quando confrontadas com escritas mais evoluídas, pondo em causa e reformulando as suas conceções sobre a escrita e apercebendo-se de um maior número de características das palavras.

Concluindo, atualmente são várias as investigações na área da linguagem escrita, que demonstram a importância dos programas de intervenção de escritas 
inventadas na promoção da evolução das escritas de crianças em idade pré-escolar. Contudo, os programas até agora desenvolvidos têm usado palavras apresentadas de forma descontextualizada, além de que têm sido organizados de modo a que, em cada uma das sessões, sejam apresentadas palavras em que a $1^{\text {a }}$ letra seja sempre a mesma e em que a introdução das várias letras seja progressiva.

Ora, sendo uma das preocupações atuais a transição deste tipo de programas para salas de jardim-de-infância, de forma a poderem ser integrados nas atividades normalmente desenvolvidas em contextos naturais, o presente trabalho procura aproximar este tipo de programas aos contextos de sala de aula. Neste sentido, o presente estudo tem como principal objetivo testar a eficácia de dois programas de escrita inventada, em que as palavras apresentadas surgiam inseridas em materiais usados geralmente em contextos de jardim-de-infância, e em que, entre os dois programas, a sequência de apresentação das várias palavras foi variável.

Partiu-se da hipótese de que os dois programas seriam eficazes na promoção do desenvolvimento da escrita das crianças dos grupos experimentais face ao grupo de controlo, apresentando um maior número de letras corretamente escritas, em pós-teste.

Coloca-se ainda como questão de investigação: Será que o número de letras corretamente escritas, em situação de pós-teste, difere significativamente entre os dois programas de intervenção?

\section{Metodologia}

\section{Participantes}

Participaram neste estudo 61 crianças (29 do sexo feminino e 32 do sexo masculino), com idades compreendidas entre os 5 e os 6 anos. Os participantes possuíam como língua materna o português e não receberam qualquer tipo de ensino formal de escrita.

Foram constituídos 2 grupos de 16 crianças e 1 grupo de 29, equivalentes em idade, nível de consciência fonológica (classificação da sílaba inicial e do fonema inicial), nível de desenvolvimento cognitivo e conhecimento das letras, como apresentado na Tabela 1.

Tabela 1.

Caracterização dos participantes relativamente às idades, consciência fonológica, nível de desenvolvimento cognitivo e conhecimento das letras

\begin{tabular}{llccc}
\hline & & N & Média & $\begin{array}{c}\text { Desvio } \\
\text { Padrão }\end{array}$ \\
\hline \multirow{3}{*}{ Idade } & Controlo & 29 & 68,24 & 2,81 \\
& Experimental 1 & 16 & 66,69 & 3,95 \\
& Experimental 2 & 16 & 68,25 & 3,30 \\
& Controlo & 29 & 17,21 & 3,26 \\
Desenvolvimento & Experimental 1 & 16 & 16,25 & 3,09 \\
Cognitivo & Experimental 2 & 16 & 17,56 & 3,95 \\
& & & & \\
Consciência & Controlo & 29 & 8,14 & 3,25 \\
Silábica & Experimental 1 & 16 & 7,69 & 1,74 \\
& Experimental 2 & 16 & 6,94 & 3,04
\end{tabular}

\begin{tabular}{lllll} 
& Controlo & 29 & 4,90 & 2,76 \\
Consciência & Experimental 1 & 16 & 5,44 & 2,07 \\
Fonémica & Experimental 2 & 16 & 4,94 & 2,57 \\
& & & & \\
\multirow{2}{*}{ Conhecimento } & Controlo & 29 & 14,48 & 5,79 \\
das letras & Experimental 1 & 16 & 15,75 & 5,26 \\
& Experimental 2 & 16 & 15,00 & 6,51 \\
\hline
\end{tabular}

De acordo com a Tabela 1, para apurar a equivalência dos grupos foram realizadas ANOVAs para a idade; $\mathrm{F}(2,58)=1.34 ; p=0.269$; para o nível desenvolvimento cognitivo, $\mathrm{F}(2,58)=0.65, p=0.525$; para a consciência silábica, $\mathrm{F}(2,58)=0.90 ; p=0.413$; para a consciência fonémica, $\mathrm{F}(2,58)=0.25 ; p=0.777$; para o conhecimento das letra, $\mathrm{F}(2,58)=0.24 ; \quad p=0.786$. Não existiam diferenças significativas entre os grupos.

\section{Instrumentos e Procedimento}

Avaliação do nível de desenvolvimento cognitivo.

Para avaliar o nível de desenvolvimento cognitivo, foi utilizada a prova Teste de Matrizes Progressivas de Raven (Raven, Court, \& Raven, 2001) na versão colorida. Atribuindo-se 1 ponto por resposta correta (cotação possível de 0 a 36 pontos).

Avaliação do nível de consciência fonológica.

Para a avaliação do nível de consciência fonológica foi utilizada a Bateria de Provas fonológicas de Silva (2008), tendo sido aplicadas as provas de tarefas de classificação ao nível da sílaba e do fonema inicial. A cotação de cada prova pode variar entre 0 e 14 pontos, atribuindo-se 1 ponto por cada resposta correta.

Avaliação do conhecimento das letras do alfabeto.

O conhecimento do nome e do som das letras foi avaliado através da apresentação de todas as letras do alfabeto português, de forma aleatória. Para cada letra reconhecida foi atribuído 1 ponto para o nome ou 1 ponto para o som da letra, num total de 23 pontos.

\section{Pré-teste e pós-teste.}

Foi pedido às crianças que escrevessem, da melhor forma que soubessem, um conjunto de 18 palavras que lhes foram ditas. Neste conjunto de palavras 12 continham os fonemas iniciais trabalhados no programa de intervenção (T,M,P,L,D,V) e 6 continham fonemas iniciais não trabalhados no programa $(\mathrm{B}, \mathrm{F}, \mathrm{R})$, com o intuito de verificar se as crianças conseguiam generalizar as correspondências dos fonemas trabalhados para os não trabalhados.

As produções escritas foram analisadas através da contagem do número de fonetizações efetuadas corretamente, por cada criança.

\section{Programa de intervenção de escrita inventada.}

Os programas foram desenvolvidos em 10 sessões durante cerca de 15/20 minutos ao longo de 5 semanas. Durante as sessões foram trabalhadas as vogais A, E, I, O e U bem como as consoantes T,M,P,L,D e V. As palavras utilizadas são, na sua maioria, dissilábicas e, grande parte delas, apresenta uma estrutura $\mathrm{CVCV}$, por ser a mais comum na língua portuguesa.

Em todas as sessões as palavras trabalhadas estavam integradas em histórias, canções, lengalengas ou poemas que começavam por ser lidos a cada grupo no início de 
cada sessão. De seguida, era pedido ao grupo de crianças que explicasse como achava que se podiam escrever um conjunto de palavras diferentes. Para cada palavra questionava-se o grupo sobre que letras se deveria escrever e sobre o "porquê" das letras escolhidas, sendo que teria que existir consenso do grupo para cada letra a escrever. Todas as crianças eram levadas a pensar e a justificar a sua resposta quando questionadas sobre a letra que usar. Quando o grupo chegava a consenso sobre cada letra a escrever, de forma a que todas as crianças pudessem ver, escrevia-se num papel as letras indicadas para cada palavra.

Após a escrita da palavra as crianças eram confrontadas com a escrita de uma criança hipotética, escrita essa alfabética, sendo que a experimentadora colocava várias questões sobre as diferenças e semelhanças da palavra escrita pelo grupo e a apresentada posteriormente, levando as crianças a debaterem qual das letras seria a mais correta para utilizar naquela palavra. Durante este debate a experimentadora nunca salientava qual seria a forma correta de escrever a palavra.

Foram realizados dois programas de intervenção, em que em ambos as letras que compunham as palavras eram as mesmas, variando a ordem pela qual as palavras eram apresentadas. No programa 1 a introdução das diferentes letras era progressiva e no programa 2 não.

No programa 1, nas sessões iniciais, as palavras trabalhadas começavam pela mesma letra. Nas primeiras seis sessões foram trabalhadas seis consoantes separadamente (T,M,P,L,D,V). A partir da sexta sessão foram apresentadas às crianças metade das palavras começadas por uma letra e metade começadas por uma outra letra, sendo trabalhas duas letras por sessão. Por fim na $10^{\text {a }}$, e última sessão, foram apresentadas todas as letras trabalhadas no programa de intervenção.

No programa 2, nas primeiras três sessões, foram apresentadas por cada sessão palavras começadas por duas das letras. A partir da quarta sessão foram apresentadas palavras começadas pelas diversas letras, sem qualquer ordem.

Programa do grupo de controlo.

O programa do grupo de controlo consistiu na leitura de histórias, sendo as sessões idênticas em duração e número das sessões do programa de escrita.

\section{Resultados}

Na Tabela 2 apresenta-se os resultados da avaliação do número de letras corretamente escritas $\left(n^{\circ}\right.$ de fonetizações) na avaliação inicial e final de escrita inventada para os grupos experimentais e de controlo.

Tabela 2.

Número de fonetizações no pré-teste e pós-teste de escrita

\begin{tabular}{llccc}
\hline & & N & Média & $\begin{array}{c}\text { Desvio } \\
\text { Padrão }\end{array}$ \\
\hline $\mathrm{N}^{\mathrm{o}}$ de & Controlo & 29 & 14,76 & 13,65 \\
fonetizações & Experimental 1 & 16 & 16,94 & 13,22 \\
(pré-teste) & Experimental 2 & 16 & 16,81 & 15,27
\end{tabular}

\begin{tabular}{lllll}
$\mathrm{N}^{\mathrm{o}}$ de & Controlo & 29 & 19,69 & 16,90 \\
fonetizações & Experimental 1 & 16 & 39,75 & 12,84 \\
(pós-teste) & Experimental 2 & 16 & 40,13 & 15,41 \\
\hline
\end{tabular}

Como é possível verificar na Tabela 2 o número de fonetizações para o grupo experimental 1 e 2 e de controlo no pré-teste é idêntico, sendo que no pós-teste os dois grupos experimentais apresentam uma média de fonetizações muito superior ao grupo de controlo.

Para analisar as diferenças entre os três grupos no que toca ao número de fonetizações corretas no pós-teste, realizou-se uma ANCOVA, usando como variável independente o grupo (experimental 1, experimental 2 ou grupo de controlo), como covariável os resultados no pré-teste (o número de fonetizações corretas) e como variável dependente o número de fonetizações corretas no pós-teste. Os resultados demonstram existirem diferenças significativas entre os grupos $(\mathrm{F}(2,57)=30.40$, $\left.p<.001, \eta^{2}=0.52\right)$. A análise post hoc, utilizando o teste LSD, mostrou diferenças entre o grupo de controlo e o grupo experimental $1(p<.001)$, bem como entre o grupo de controlo e o grupo experimental $2(p<.001)$, não tendo sido encontradas diferenças entre os dois grupos experimentais $(p=0.881)$.

A Figura 1 mostra a escrita de 5 das 18 palavras escritas por uma criança do grupo de controlo no pré e pós-teste.

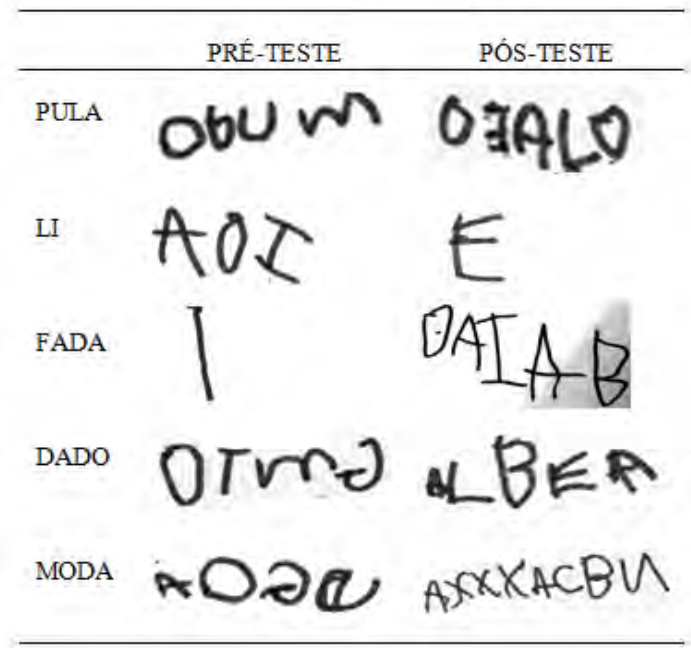

Figura 1. Exemplos de escritas de uma criança do grupo de controlo

Como é visível na figura esta criança utilizou um conjunto de letras arbitrárias para escrever as palavras propostas, tanto no pré como no pós-teste.

A Figura 2 mostra a escrita de 5 das 18 palavras escritas por uma criança do grupo experimental no pré e pós-teste. 


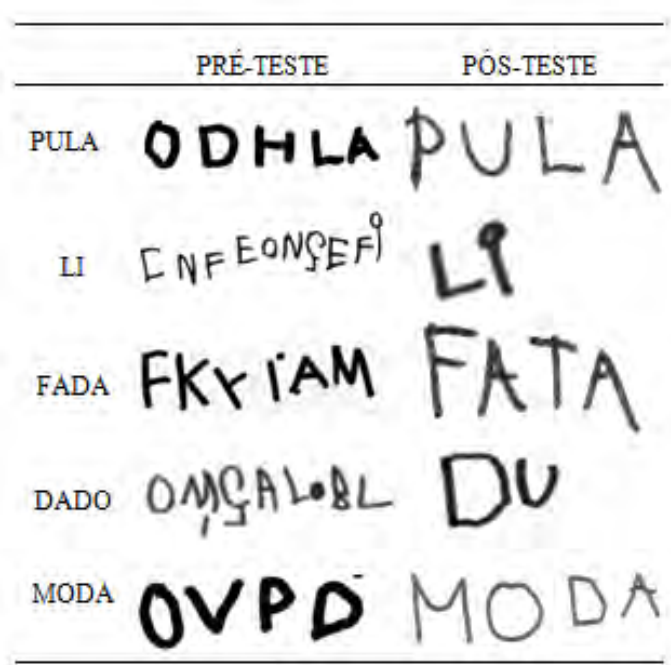

Figura 2. Exemplos de escritas de uma criança do grupo de um experimental

Como é possível verificar na figura esta criança, inicialmente, colocava apenas uma letra da primeira silaba da palavra corretamente, escrevendo depois um conjunto de letras ao acaso. Já no pós-teste a criança escreveu corretamente a grande maioria das palavras, utilizando mais do que uma letra por sílaba, sendo as letras utilizadas as corretas.

Assim, é possível verificar que ambos os programas de escrita inventada tiveram um impacto na evolução do número de fonetizações e na qualidade das escritas das crianças dos grupos experimentais.

\section{Discussão}

O presente estudo tem como principal objetivo testar a eficácia de dois programas de escrita inventada, em que as palavras apresentadas surgiam inseridas em materiais usados geralmente em contextos de jardim-de-infância, e em que, entre os dois programas, a sequência de apresentação das várias palavras foi variável.

As crianças sujeitas aos programas apresentaram, no pós-teste, uma média de fonetizações muito superior ao grupo de controlo, tendo-se verificado que as diferenças eram estatisticamente significativas, confirmando-se assim a nossa hipótese de que os dois programas seriam eficazes. Estes resultados vão ao encontro dos estudos de Alves Martins, Salvador e Albuquerque (2014) e de Alves Martins, Salvador, Albuquerque e Silva (2014), que também desenvolveram programas de intervenção de escritas inventadas em pequeno grupo e verificaram que o grupo experimental apresentou melhores resultados na escrita de palavras, no pós-teste, do que o grupo de controlo. Assim, estes estudos fornecem suporte empírico e demonstram a importância de se desenvolver este tipo de programas nas salas de jardim-de-infância, pois a estimulação das escritas inventadas é uma mais valia nas práticas pedagógicas, no sentido de facilitar o processo de alfabetização e de procurar prevenir dificuldades de aprendizagem da leitura e escrita (Alves Martins \& Silva, 2006).
O presente estudo teve também como objetivo compreender se existiriam diferenças significativas no número de fonetizações, em situação de pós-teste, entre os dois programas de intervenção. Através dos resultados verificou-se que não existem diferenças significativas entre os dois programas de intervenção. Estes resultados sugerem que, mesmo quando nas sessões a $1^{\text {a }}$ letra apresentada não é sempre a mesma e em que a introdução das várias letras não é progressiva, como aconteceu no programa experimental 2 , as crianças continuam a progredir nas suas escritas, não sendo esta uma variável que influencie a eficácia do programa.

Assim sendo, os resultados obtidos no presente estudo permitem aproximar estes programas às práticas de sala de aula de jardim-de-infância. A metodologia aplicada nos programas de intervenção em que as crianças pensam sobre a forma como se escreve determinada palavra e comparam com a escrita mais avançada de uma criança hipotética, tendo que discutir com o grupo qual a forma mais correta de se escrever a palavra é facilmente aplicável num contexto de jardim-de-infância, em pequeno grupo (Alves Martins, Mata \& Silva, 2014). Para além disso, podemos pensar que, depois dos resultados obtidos no presente estudo, as palavras propostas às crianças não têm que ser tão estruturadas como anteriormente se pensava, sendo por isso mais fácil para o educador trabalhar as palavras que surgem naturalmente em cada contexto trabalhado.

Em futuros estudos será interessante compreender o papel do adulto, durante a discussão das palavras em grupo, sistematizando as ajudas que o adulto deve dar às crianças de forma a que estas tenham um maior sucesso na aquisição da literacia.

\section{Referências}

Adams, M. J. (1998). Beginning to read: Thinking and learning about print (10th ed.). Cambridge, Massachusetts: MIT press.

Alves Martins, M., Albuquerque, A., Salvador, L., \& Silva, C. (2013). The impact of invented spelling on early spelling and reading. Journal of Writing Research, 5(2), 215-237.

http://dx.doi.org/10.17239/jowr-2013.05.02.3

Alves Martins, M., Mata, L., \& Silva, C. (2014). Conceptualizações sobre a linguagem escrita Percursos de investigação. Análise Psicológica, 2 (XXXII), 135-143. http://dx.doi.org/10.14417/ap.841

Alves Martins, M., \& Niza, I. (1998). Psicologia da Aprendizagem da Linguagem Escrita. Lisboa: Universidade Aberta.

Alves Martins, M., Salvador, L., \& Albuquerque, A. (2014). Programas de escrita inventada em pequeno grupo e leitura em crianças de idade pré-escolar. In F. H. Veiga (Coord.), Envolvimento dos Alunos na Escola: Perspetivas Internacionais da Psicologia e Educação"/ "Students' Engagement in School: International Perspectives of Psychology and Education (pp. 660-677). Lisboa: Instituto de Educação da Universidade de Lisboa.

Alves Martins, M., Salvador, L., Albuquerque, A., \& Silva, C. (2014). Invented spelling activities in small 
groups and early spelling and reading. Educational Psychology, 1 (1), 1-15.

http://dx.doi.org/10.1080/01443410.2014.950947

Alves Martins, M., \& Silva, A. C. (1999). Os nomes das letras e a fonetização da escrita. Análise Psicológica, 1 (XVII), 49-63.

Alves Martins, M., \& Silva, C. (2001). Letter names, phonological awareness and the phonetization of writing. European Journal of Psychology of Education, 16 (4), 605-617. http://dx.doi.org/10.1007/BF03173200

Alves Martins, M., \& Silva, C. (2006). The impact of invented spelling on phonetic awareness. Learning and Instruction, 16 (1), 41-56. http://dx.doi.org/10.1016/j.learninstruc.2005.12.005

Alves Martins, M., \& Silva, C. (2009). Two spelling programmes that promote understanding of the alphabetic principle in preschool children. Journal of Writting Research, 1 (3), 225-240. http://dx.doi.org/10.17239/jowr-2009.01.03.3

Chomsky, C. (1970). Reading, writing and phonology. Harvard Educational Review, 40 (2), 287-309. http://dx.doi.org/10.17763/haer.40.2.y7u0242 x76w05624

Ferreiro, E. \& Teberosky, A. (1999). Psicogênese da língua escrita. Porto Alegre: Artmed

Mann, V. A. (1993). Phoneme awareness and future reading ability. Journal of Learning Disabilities, 26 (4), 259-269. http://dx.doi.org/10.1177/0022219493026004 06

Ouellette, G., \& Sénéchal, M. (2008). Pathways to literacy: a study of invented spelling and its role in learning to read. Child Development, 74 (4), 899-913. http://dx.doi.org/10.1111/j.1467-8624.2008. 01166.x
Ouellette, G., Sénéchal, M., \& Haley, A. (2013). Guiding children's invented spellings: A gateway into literacy learning. The Journal of Experimental Education, 81 (2), 261-279. http://dx.doi.org/10.1080/00220973.2012.699903

Raven, J., Court, J., \& Raven, J. (2001). Raven- Matrices Progressivas ( $3^{\mathrm{a}}$ ed.). Madrid: TEA- Publicaciones de Psicología Aplicada.

Read, C. (1971). Pre-school children's knowledge of English phonology. Harvard Educational Review, 41 (1), 1-34.

Silva, A. C. (2008). Bateria de Provas Fonológicas. Lisboa: ISPA.

Treiman, R. (1998). Why spelling? The benefits of incorporating spelling into beginning to reading instructions. In J. L. Metsala, \& L. C. Ehri (Eds.), Word recognition in beginning literacy (pp. 289-313). London: Lawrence Erlbaum Associates Publishers.

Vygotsky, L. (1978). Mind in society: the development of higher psychological processes. Cambridge: Harvard University Press 